\title{
3
}

\section{MEASURING WEALTH: IMPLICATIONS FOR SUSTAINABLE DEVELOPMENT ${ }^{1}$}

\author{
Kevin J Mumford
}

\section{Introduction}

This chapter is about measurement, not about evaluating specific policies. What we measure determines our focus when choosing policies and strongly influences how we view our political leaders and how we vote. As the costs of data collection and analysis have dropped, a host of new indices and dashboards of economic, demographic, social and environmental measures are posted for public consumption. One of the axioms of choice theory is that more of a good is preferred to less. The axiom can fail, however, when it comes to information. An overload of information can leave us worse off if the host of measures distracts us from what is relevant.

In this paper, I describe how we measure current wellbeing, what economic theory tells us about how to measure intergenerational wellbeing, and how to measure wealth. This paper provides a context in which to assess the economic and political value of wealth accounting. I present income and wealth data from several specific countries to illustrate the methods,

\footnotetext{
1 My thinking on this subject has benefited greatly from conversations and collaboration with Kenneth Arrow, Partha Dasgupta, Anantha Duraiappah, Larry Goulder, and Pablo Muńoz.
} 
not to evaluate the political choices of those countries. Rather than trying to make a point about sub-optimal policies in the 1990s and 2000s in certain countries, this paper has the more far-reaching goal of influencing policy choices indirectly by changing what we measure.

\section{Measuring current wellbeing}

In this paper, I use the term 'current wellbeing' to describe the standard of living enjoyed in a country. I do not assume that people or governments have perfect foresight, nor do I assume that their policies and investment choices place the country on an optimal growth path. I use the term 'intergenerational wellbeing' to describe the long-run standard of living that will be enjoyed by a country's future generations.

The System of National Accounts (SNA) is the international standard for measuring consumption, investment, production and government expenditure flows. The SNA is designed to measure gross domestic product (GDP), which is the value of market production within a country and is the most widely used measure of economic activity. GDP is a flow variable, it measures current production of goods and services, not future production, and thus is commonly used as a proxy for the current wellbeing of a country.

The machines, computers and other capital assets used to produce goods and services wear out over time and become obsolete. Some fraction of total output has to be dedicated to maintaining the capital stock and replacing obsolete assets just to keep the stock of capital assets from declining. Net domestic product (NDP) is calculated by subtracting the depreciation of capital assets from GDP. As a measure of current wellbeing, NDP is generally better than GDP because goods and services dedicated to upkeep of capital assets are not available for consumption. ${ }^{2}$ The reason GDP has been more widely used is that measuring depreciation of capital assets is difficult and, in practice, historical movements in NDP closely mirrored those in GDP, at least until the 1990s. Capital assets today have a shorter life expectancy than those of several decades ago, which means there is a higher rate of depreciation.

2 If investment is less than depreciation, the stock of capital assets will decline, which reduces the productive capacity of the county. This implies that wellbeing is higher in the current period than it will be in the future. In this scenario, GDP may be the better measure of current wellbeing. 
Just like GDP, NDP is a flow variable, but Weitzman (1976) shows that NDP is the appropriate measure of intergenerational wellbeing in a world where (1) all goods and services are purchased in a competitive market and where (2) governments, firms and households optimally make savings and consumption decisions to maximise intergenerational wellbeing. Under these conditions, changes in NDP represent changes in both current wellbeing and intergenerational wellbeing. This is because the present discounted value of all future NDP is equivalent to the current wealth of the county.

My view is that neither of Weitzman's (1976) two assumptions holds. Many of the goods and services that we value are not purchased in a competitive market and are therefore not included in NDP. We value family, friendships, safety, meaningful work and recreation time. These are important sources of happiness and cannot generally be purchased directly. They all, however, depend on goods and services. For example, sporting goods and travel services are associated with recreation. Educational services help us to find meaningful work, develop friendships and become the kind of person we want to be. Therefore, NDP indirectly measures these important sources of happiness, at least to the extent that they are correlated with the consumption of market goods and services.

However, NDP does not take into account our current enjoyment of the natural environment. Polluted air and water have a large negative effect on current wellbeing, but they are not included in NDP because there is no competitive market for these environmental goods. In fact, NDP does not even account for changes in the stock of fossil fuels, minerals and forests that are bought and sold on markets. Hartwick (1990) points out that the depreciation of environmental capital assets that are employed in production should be subtracted from GDP when calculating NDP but, nearly 30 years later, this is still not the standard for the headline statistic. One must refer to the satellite accounts for environmental depreciation.

The System of Integrated Environmental and Economic Accounting (SEEA) has developed methods for estimating the social value of environmental services. Note that there is controversy about what methods to increase stocks of natural capital; that is, forest or fisheries growth. Should these natural increases be added to the measure of output? In principle, NDP accounting should be symmetric with the depreciation of all capital and environmental assets used in production subtracted from GDP and natural capital growth should be added. A related question 
is whether reductions of environmental services that have little direct impact on production be subtracted from GDP. In principle, the value of environmental services (for example, the direct benefit of clean air and water) as well as the value of leisure time and the value of unpaid work should all be treated identically to services produced by the market and added to GDP. Such a measure is generally called 'green GDP' and proponents argue that it is a better measure of current wellbeing. ${ }^{3}$

The World Banks world development indicators measure the value of natural capital stock depletion for most countries from 1970 to 2015 (World Bank 2016). Barbier (2016) shows how to construct a natural capital depreciation rate that can be used to calculate green GDP or as a 'green' national income measure.

Why not dispense with these adjusted GDP measures and directly measure happiness instead? I believe that attempts to directly measure happiness are unlikely to be useful. Happiness surveys essentially ask people to report their happiness by selecting one of a few ordered categories such as 'very happy', 'somewhat happy', 'not very happy', etc. One can assign numerical values to these categories and then report how the average level of happiness in a country changes over time or in response to a certain policy. However, Bond and Lang (2014) show that it not possible to rank countries by happiness without imposing restrictive assumptions. They show that producing a cardinal measure of happiness from such surveys is not possible. Without some revolutionary advance in how we directly measure wellbeing, we are resigned to inferring wellbeing from GDP measures.

There is a fundamental problem with NDP, green GDP, and other adjusted GDP measures. They do not measure true economic growth, which is an expansion in the capacity to produce goods and services. They are only measures of the production or income itself. Mumford (2016) provides an analogy to attempting to evaluate firms by looking only at the income statement and ignoring the balance sheet, which reports the value of all assets and liabilities. If Weitzman's (1976) second assumption holds, that countries (or firms in the analogy) are on an optimal growth path, then we can safely ignore the balance sheet because the firm's current

3 See Harper et al. (2009) for a description of the US Bureau of Economic Analysis (BEA) and Bureau of Labour Statistics (BLS) efforts to value unpaid work by using productivity measures in the BEA satellite accounts. 
profits characterise the firm's future profit potential. On the other hand, if some firms occasionally make short-sighted decisions to increase current profits at the expense of future profits, then ignoring the balance sheet is a mistake.

Arguments for the assumption that countries are on an optimal growth path are unconvincing. Examples of governments, firms and households making myopic decisions abound. No green GDP-like measure will be able to indicate if a country is over-consuming and underinvesting (Stiglitz et al. 2008).

\section{Measuring intergenerational wellbeing}

Here, I will review the methods used to measure intergenerational wellbeing and evaluate the sustainability of a country's consumption and investment policies. We begin by ignoring distributional considerations and population growth. Under these assumptions, the wellbeing of a country in period $t$ is defined as $U(C)$. Current wellbeing is increasing in consumption per capita, or $C_{t}$. Consumption is an aggregation of the value of the goods and services consumed. There are trade-offs between the various goods and services and thus various ways of achieving any particular level of wellbeing $U(C)$. For example, consumption of a sufficient quantity of additional goods and services can compensate for an increase in air pollution. Similarly, people would be willing to give up some positive quantity of goods and services in exchange for less-polluted air. The amount of other goods and services that people are willing to give up for less-polluted air defines the social value of the flow of clean-air services.

Consumption growth, $C_{t+1} \geq C_{t}$ means that people are better off at the moment, but it does not guarantee that people will enjoy a higher standard of living in the future. Intergenerational wellbeing at period $t$ is defined by Dasgupta and Mäler (2000) as the discounted sum of the flow of wellbeing into the infinite future

$$
V_{t}=U\left(C_{t}\right)+(1-\delta) U\left(C_{t+1}\right)+(1-\delta)^{2} U\left(C_{t+2}\right)+\mathrm{K}=\sum_{s=0}^{\infty}(1-\delta)^{s} U\left(C_{t+s}\right)
$$

where $\delta$ is the discount rate. Intergenerational wellbeing is the discounted sum of wellbeing in the current and all future periods. Without the ability to forecast future consumption, there is no way to directly measure $V_{t}$. 
Arrow et al. (2012) define sustainability as non-declining intergenerational wellbeing $V_{t+s} \geq V_{t}$. A country's path may be sustainable even if it is investing less than would be optimal given the social discount rate, the utility function, and production function. All that is required for development to be sustainable is that intergenerational wellbeing is not declining.

We cannot directly measure intergenerational wellbeing, but we can measure the social value of capital assets used to produce goods and services. Dasgupta and Mäler (2000) prove that potential intergenerational wellbeing increases if and only if the productive base increases. Conceptually, output (all goods and services) flow from capital stocks according to the production function

$$
Y_{t}=\alpha_{t} f_{t}\left(K_{1 t}+K_{2 t}+K_{3 t}+K\right)
$$

where $\alpha_{t}$ denotes the level of productivity in period $t$ and $K_{i t}$ denotes capital stock of type $i$.

Individual types of capital have an associated social value in producing wellbeing, as denoted by $P_{i t}$. For assets with no externalities that are sold in a competitive market, the market price is a good approximation of the social value. With prices and quantities, wealth is defined as:

$$
W_{t}=P_{\alpha t} \alpha_{t}+\sum_{i} P_{i t} K_{i t}
$$

It is important to note that current prices should always be used as they reflect the current value in production, as determined by the function $f_{t}($.$) , and social values. This means that wealth in the previous period is$ defined as

$$
W_{t-1}=P_{\alpha t} \alpha_{t-1}+\sum_{i} P_{i t} K_{i t-1}
$$

If it were possible, we would use future prices rather than the current prices because future prices reflect the production trade-offs and social values that future generations will face. For most assets, however, there is no way for us to know what the future prices will be.

With the above definitions, we can restate the Dasgupta and Mäler (2000) result as saying that the economic development from period $t-1$ to period $t$ was sustainable if and only if $W_{t} \geq W_{t-1}$. Note that there is no requirement that the composition of consumption stay the same in future periods. Sustainable development does not imply everyone will consume as much of every good or service as they do now. Similarly, sustainable 
development does not imply that every form of capital must be sustained. A country that reduces one form of capital and increases another form of capital has experienced sustainable growth if the social value of the capital gain is larger than the social value of the capital loss. To allow for population change, Dasgupta (2004) and Arrow et al. (2003) describe the conditions under which one can restate the Dasgupta and Mäler (2000) result in terms of wealth per capita.

The SNA measure of produced capital (fixed assets) is frequently referred to as national wealth. Produced capital is clearly an important part of the production process, but it is not the most important form of capital. In a production function with only human capital (labour) and produced capital, human capital is generally estimated to have a 60 per cent weight with the remaining 40 per cent attributed to produced capital. ${ }^{4}$ Natural resources like oil, coal, natural gas, forests, fisheries and minerals are also important parts of the production process that are not included in the SNA produced capital measure. Arrow et al. (2012) call the sum of all these types of capital comprehensive wealth or inclusive wealth.

In practice, measuring capital stocks is difficult. For example, proven oil reserves increase every year. This is not because nature is producing oil faster than we can extract it. It is because we are inventing technologies for finding and extracting the oil faster than we extract it. So, rather than use the proven reserves as reported in earlier years, we take the current proven reserves and add the extraction estimates for each intervening year to arrive at values for past stocks. Note also that capital can be located in one country, but owned by the citizens of another country. Future returns from the capital asset generally flow to the owner of the asset, regardless of the location.

An even more problematic example is how to measure the stock of human capital. Countries have a large number of worker types as defined by their skills. Within each skill group, there are different expected years of work remaining depending on age and gender. This dramatically increases the number of human capital stock types for which one needs a social value.

4 The labour share of national income was constant at about 66 per cent for decades, but has recently declined to about 60 per cent, which suggests that aggregate production has become more capital intensive. 
Estimating the prices of social values is even more challenging than measuring the capital stocks. For example, we need an estimate of the discounted lifetime contribution to production for each type of worker. The discount sum of future wages is the most straightforward (though not easy) way to calculate this. Estimating social values for types of natural capital where there is no market is particularly challenging.

\section{Measuring changes in inclusive wealth}

Arrow et al. (2012) define comprehensive or inclusive investment as the change in comprehensive or inclusive wealth:

$$
\Delta W_{t}=P_{\alpha t} \Delta \alpha_{t}+\sum_{i} P_{i t} \Delta K_{i t}
$$

Note that we are holding the prices fixed so changes in inclusive wealth are either the result of a change in the stock of one or more types of capital or a change in productivity. Capital depreciation and extraction deplete the stock while investment and natural growth (for renewable resources) increase the stock. Kurniawan and Managi (2018) show how to estimate productivity (TFP) in the context of inclusive wealth measurement.

Rather than directly measuring capital stocks as in Arrow et al. (2012) and the Inclusive Wealth Reports (UNU-IHDP \& UNEP 2012, 2014, 2018), the World Bank (2011) directly measures comprehensive investment, which it describes as genuine savings, genuine investment or adjusted net savings. In this form, the Dasgupta and Mäler (2000) result is simply $\Delta W_{t} \geq 0$. Empirically, genuine savings is derived from the SNA measure of gross national savings. The first step is to subtract capital depreciation, called capital consumption of produced assets in the SNA. Then, spending on education is added along with changes in the value of as many types of natural capital as possible.

While the World Bank and Inclusive Wealth Report take different approaches to measuring the same object, they are more similar than they are different. The theoretical grounding of either wealth-based approach is appealing to economists as compared to the host of indices and indicator dashboards. ${ }^{5}$

5 The Inclusive Wealth Report (UNU-IHDP \& UNEP 2014) uses data from 140 countries from 1990 to 2010 to measure inclusive wealth. This is labelled as the 'inclusive wealth index', which is a poor choice. Inclusive wealth is a theoretically grounded comprehensive measurement of wealth and is not an index. Indices are generally ad-hoc combinations of various measures with no theoretical 


\section{Empirical evidence of sustainable development in Asia}

In this section, I present inclusive wealth measures for several Asian countries and the United States for 1990-2010. Table 3.1 gives the five-year percentage change in three types of capital per capita: produced, natural (forests, minerals, energy) and human (education). The five-year percentage change in productivity is also estimated from BEA and OECD data. The five-year change in GDP per capita is provided for comparison.

Table 3.1. Percentage change in capital stocks and inclusive wealth

\begin{tabular}{|l|c|c|c|c|}
\hline \multicolumn{1}{|l|}{ Australia } & $\mathbf{1 9 9 1 - 9 5}$ & $\mathbf{1 9 9 6 - 2 0 0 0}$ & $\mathbf{2 0 0 1 - 0 5}$ & $\mathbf{2 0 0 6 - 1 0}$ \\
\hline Produced capital & $10.2 \%$ & $15.5 \%$ & $18.9 \%$ & $19.2 \%$ \\
\hline Natural capital & $-6.6 \%$ & $-7.0 \%$ & $-8.2 \%$ & $-13.0 \%$ \\
\hline Human capital & $0.7 \%$ & $0.7 \%$ & $3.4 \%$ & $5.3 \%$ \\
\hline Productivity & $5.9 \%$ & $8.1 \%$ & $3.1 \%$ & $0.6 \%$ \\
\hline Inclusive wealth & $5.5 \%$ & $8.8 \%$ & $6.0 \%$ & $4.0 \%$ \\
\hline GDP & $11.1 \%$ & $14.7 \%$ & $11.4 \%$ & $4.8 \%$ \\
\hline
\end{tabular}

\begin{tabular}{l|l|c|c|c|}
\hline \multicolumn{1}{l|}{ China } & $\mathbf{1 9 9 0 - 9 5}$ & $\mathbf{1 9 9 5 - 2 0 0 0}$ & $\mathbf{2 0 0 0 - 0 5}$ & $\mathbf{2 0 0 5 - 1 0}$ \\
\hline Produced capital & $45.7 \%$ & $56.5 \%$ & $61.5 \%$ & $73.4 \%$ \\
\hline Natural capital & $-6.6 \%$ & $-7.4 \%$ & $-7.7 \%$ & $-6.8 \%$ \\
\hline Human capital & $7.2 \%$ & $6.0 \%$ & $4.0 \%$ & $5.5 \%$ \\
\hline Productivity & $38.2 \%$ & $11.5 \%$ & $17.8 \%$ & $11.5 \%$ \\
\hline Inclusive wealth & $42.9 \%$ & $18.4 \%$ & $27.9 \%$ & $30.8 \%$ \\
\hline GDP & $68.3 \%$ & $44.7 \%$ & $54.5 \%$ & $65.8 \%$ \\
\hline
\end{tabular}

\begin{tabular}{|l|c|c|c|c|}
\hline \multicolumn{1}{|l|}{ India } & $\mathbf{1 9 9 0 - 9 5}$ & $\mathbf{1 9 9 5 - 2 0 0 0}$ & $\mathbf{2 0 0 0 - 0 5}$ & $\mathbf{2 0 0 5 - 1 0}$ \\
\hline Produced capital & $18.9 \%$ & $24.5 \%$ & $32.5 \%$ & $48.1 \%$ \\
\hline Natural capital & $-10.8 \%$ & $-9.9 \%$ & $-9.9 \%$ & $-9.6 \%$ \\
\hline Human capital & $1.0 \%$ & $4.5 \%$ & $3.4 \%$ & $2.7 \%$ \\
\hline Productivity & $5.7 \%$ & $13.3 \%$ & $8.4 \%$ & $12.0 \%$ \\
\hline Inclusive wealth & $5.1 \%$ & $16.5 \%$ & $12.8 \%$ & $20.1 \%$ \\
\hline GDP & $16.4 \%$ & $21.2 \%$ & $29.5 \%$ & $39.2 \%$ \\
\hline
\end{tabular}


ACHIEVING INCLUSIVE GROWTH IN THE ASIA PACIFIC

\begin{tabular}{|l|c|c|c|c|}
\hline Indonesia \\
\hline Produced capital & $\mathbf{1 9 9 0 - 9 5}$ & $\mathbf{1 9 9 5 - 2 0 0 0}$ & $\mathbf{2 0 0 0 - 0 5}$ & $\mathbf{2 0 0 5 - 1 0}$ \\
\hline Natural capital & $-13.7 \%$ & $27.0 \%$ & $15.3 \%$ & $23.4 \%$ \\
\hline Human capital & $3.3 \%$ & $-11.3 \%$ & $-9.6 \%$ & $-10.1 \%$ \\
\hline Productivity & $6.0 \%$ & $-20.1 \%$ & $8.5 \%$ & $0.2 \%$ \\
\hline Inclusive wealth & $3.7 \%$ & $-19.5 \%$ & $7.6 \%$ & $2.4 \%$ \\
\hline GDP & $34.8 \%$ & $-3.1 \%$ & $18.3 \%$ & $25.0 \%$ \\
\hline
\end{tabular}

\begin{tabular}{|l|c|c|c|c|}
\hline Japan & $\mathbf{1 9 9 0 - 9 5}$ & $\mathbf{1 9 9 5 - 2 0 0 0}$ & $\mathbf{2 0 0 0 - 0 5}$ & $\mathbf{2 0 0 5 - 1 0}$ \\
\hline Produced capital & $17.9 \%$ & $11.8 \%$ & $7.0 \%$ & $4.3 \%$ \\
\hline Natural capital & $-2.5 \%$ & $-0.9 \%$ & $-3.9 \%$ & $-1.4 \%$ \\
\hline Human capital & $4.2 \%$ & $2.3 \%$ & $0.9 \%$ & $0.1 \%$ \\
\hline Productivity & $3.1 \%$ & $3.4 \%$ & $4.4 \%$ & $0.5 \%$ \\
\hline Inclusive wealth & $11.5 \%$ & $8.9 \%$ & $7.4 \%$ & $2.1 \%$ \\
\hline GDP & $5.3 \%$ & $3.8 \%$ & $6.1 \%$ & $0.5 \%$ \\
\hline
\end{tabular}

\begin{tabular}{|l|c|c|c|c|}
\hline Malaysia \\
\hline Produced capital & $\mathbf{1 9 9 0 - 9 5}$ & $\mathbf{1 9 9 5 - 2 0 0 0}$ & $\mathbf{2 0 0 0 - 0 5}$ & $\mathbf{2 0 0 5 - 1 0}$ \\
\hline Natural capital & $-16.1 \%$ & $-17.0 \%$ & $-17.7 \%$ & $-16.5 \%$ \\
\hline Human capital & $10.5 \%$ & $5.1 \%$ & $1.7 \%$ & $5.4 \%$ \\
\hline Productivity & $-1.6 \%$ & $-7.7 \%$ & $2.4 \%$ & $-3.8 \%$ \\
\hline Inclusive wealth & $3.7 \%$ & $-5.8 \%$ & $1.1 \%$ & $-1.1 \%$ \\
\hline GDP & $38.2 \%$ & $11.8 \%$ & $13.1 \%$ & $14.5 \%$ \\
\hline
\end{tabular}

\begin{tabular}{|l|c|c|c|c|}
\hline South Korea & $\mathbf{1 9 9 0 - 9 5}$ & $\mathbf{1 9 9 5 - 2 0 0 0}$ & $\mathbf{2 0 0 0 - 0 5}$ & $\mathbf{2 0 0 5 - 1 0}$ \\
\hline Produced capital & $68.7 \%$ & $40.5 \%$ & $28.7 \%$ & $21.5 \%$ \\
\hline Natural capital & $0.2 \%$ & $2.7 \%$ & $3.8 \%$ & $1.0 \%$ \\
\hline Human capital & $7.9 \%$ & $4.5 \%$ & $3.8 \%$ & $2.4 \%$ \\
\hline Productivity & $2.1 \%$ & $3.6 \%$ & $4.9 \%$ & $5.7 \%$ \\
\hline Inclusive wealth & $19.2 \%$ & $16.3 \%$ & $15.8 \%$ & $14.4 \%$ \\
\hline GDP & $40.7 \%$ & $25.1 \%$ & $21.8 \%$ & $17.6 \%$ \\
\hline
\end{tabular}




\begin{tabular}{|l|c|c|c|c|}
\hline United States & $\mathbf{1 9 9 0 - 9 5}$ & $\mathbf{1 9 9 5 - 2 0 0 0}$ & $\mathbf{2 0 0 0 - 0 5}$ & $\mathbf{2 0 0 5 - 1 0}$ \\
\hline Produced capital & $10.7 \%$ & $18.6 \%$ & $17.2 \%$ & $9.9 \%$ \\
\hline Natural capital & $-7.4 \%$ & $-8.3 \%$ & $-6.4 \%$ & $-5.8 \%$ \\
\hline Human capital & $-0.3 \%$ & $0.9 \%$ & $2.5 \%$ & $1.5 \%$ \\
\hline Productivity & $3.5 \%$ & $7.3 \%$ & $8.3 \%$ & $3.5 \%$ \\
\hline Inclusive wealth & $4.4 \%$ & $10.7 \%$ & $13.2 \%$ & $6.5 \%$ \\
\hline GDP & $7.8 \%$ & $16.6 \%$ & $7.2 \%$ & $-0.9 \%$ \\
\hline
\end{tabular}

Source. Author's calculations, the UNU-IHDP and UNEP (2014), and OECD statistics

Table 3.1 makes it clear that GDP growth does not necessarily indicate growth in wealth. For example, Indonesia and Malaysia both have periods of GDP growth that occur simultaneously with decreases in inclusive wealth. GDP growth tends to be larger than inclusive wealth growth for most countries. Several countries have five-year GDP growth rates that are 10 or even 20 percentage points higher than the five-year growth rate in inclusive wealth (even with productivity growth included). A counter example is Japan, which has a higher rate of inclusive wealth growth than GDP growth in the four time periods considered.

Our measure of natural capital includes agricultural land, forests, mineral resources, energy resources and fisheries. The costs of global climate change, modelled as a global public bad, increased during the period. Similarly, the ecological services performed by forests and coastal waters have decreased. Across most Asian countries, natural capital has experienced large decreases while produced and human capital have experienced large increases. An exception is South Korea, where natural capital is increasing, driven by renewable natural resources including forests. Those countries with a decline of inclusive wealth in any one of those time periods were simply extracting more from the environment than they were investing in education, roads, housing, production facilities and equipment. For some countries, including the United States, China and India, the per cent reduction in natural capital is declining over time. In other countries, including Australia, the decline in natural capital is accelerating. In Australia's case, this is primarily due to mining. 


\section{Conclusion}

Wealth accounting allows us to measure the productive base that provides for the wellbeing of future generations. As a theoretically based measure of intergenerational wellbeing, inclusive wealth is the appropriate way to evaluate if economic development is sustainable. The methods for calculating inclusive wealth do not require assumptions about optimality, nor do they require forecasts of future quantities. The methods do, however, require high-quality quantity and price data for a wide variety of capital assets.

Wealth accounting is not going to replace GDP. Flow variables, like GDP, are directly related to current wellbeing. Stock variables, like inclusive wealth, are instead related to potential intergenerational wellbeing. An increase in inclusive wealth implies that future citizens will inherit a larger productive base and will therefore be able to enjoy higher levels of wellbeing. This, however, is only a statement about the potential intergenerational wellbeing, not a claim that wellbeing will definitely be higher.

I encourage government statistical offices to augment their wealth accounts by measuring the value of human and natural capital. Just as firms create annual balance sheets, governments should prepare annual wealth accounts. Citizens need wealth measures to be able to hold their government accountable for the policies it enacts. Without wealth accounting, all citizens can do is look at the usually strong GDP per capita growth rate and hope that it will keep going up indefinitely.

\section{References}

Arrow, KJ, Dasgupta, P \& Mäler, KG (2003). 'The genuine savings criterion and the value of population', Economic Theory, 21(2), 217-25. doi.org/10.1007/ s00199-002-0335-2.

Arrow, KJ, Dasgupta, P, Goulder, LH, Mumford, KJ \& Oleson, K (2012). 'Sustainability and the measurement of wealth', Environment and Development Economics, 17(3), 317-53. doi.org/10.1017/S1355770X12000137.

Barbier, EB (2016). 'Natural capital and wealth in the 21st century', Eastern Economic Journal, 43(3), 391-405. doi.org/10.1057/s41302-016-0013-x.

Bond, TN \& Lang, K (2014). 'The sad truth about happiness scales', NBER Working Paper, No. 19950, March, www.nber.org/papers/w19950. 
Dasgupta, P (2004 (2001)). Human wellbeing and the natural environment, 2nd edn. Oxford University Press.

Dasgupta, P \& Mäler, KG (2000). 'Net national product, wealth, and social wellbeing', Environment and Development Economics, 5(1), 69-93. doi.org/ 10.1017/S1355770X00000061.

Harper, MJ, Moulton, BR, Rosenthal, S \& Wasshausen, DB (2009). 'Integrated GDP-productivity accounts', American Economic Review Papers and Proceedings, 99(2), 74-79. doi.org/10.1257/aer.99.2.74.

Hartwick, J (1990). 'Natural resources, national accounting and economic depreciation', Journal of Public Economics, 43(3), 291-304. doi.org/10.1016/ 0047-2727(90)90002-Y.

Kurniawan, R \& Managi, S (2018). 'Linking wealth and productivity of natural capital for 140 countries between 1990 and 2014', Social Indicators Research, 1-20. doi.org/10.1007/s11205-017-1833-8.

Mumford, KJ (2012). 'Measuring inclusive wealth at the state level in the United States'. In UNU-IHDP \& UNEP, Inclusive Wealth Report 2012: Measuring progress towards sustainability (pp 69-86). Cambridge University Press.

_ (2016). 'Prosperity, sustainability and the measurement of wealth', Asia \& the Pacific Policy Studies, 3(2), 226-34. doi.org/10.1002/app5.132.

Stiglitz, J, Sen, A \& Fitoussi, J-P (2008). Report by the Commission on the Measurement of Economic Performance and Social Progress. Paris.

UNU-IHDP \& UNEP (2012). Inclusive Wealth Report 2012: Measuring progress towards sustainability. Cambridge University Press.

_ (2014). Inclusive Wealth Report 2014: Measuring progress towards sustainability. Cambridge University Press.

- (2018). Inclusive Wealth Report 2018: Measuring sustainability and wellbeing, wedocs.unep.org/xmlui/handle/20.500.11822/27597.

Weitzman, ML (1976). 'On the welfare significance of national product in a dynamic economy', The Quarterly Journal of Economics, 90(1), 156-62. doi.org/10.2307/1886092.

World Bank (2011). The changing wealth of nations: measuring sustainable development in the new millennium. Washington DC.

(2016). World development indicators. Washington DC: World Bank, data. worldbank.org/data-catalog/world-development-indicators. 
This text is taken from Achieving Inclusive Growth in the Asia Pacific, edited by Adam Triggs and Shujiro Urata, published 2020 by ANU Press, The Australian National University, Canberra, Australia.

doi.org/10.22459/AIGAP.2020.03 